\title{
Hydropower generator speed control using fuzzy software tool
}

\author{
Ngang, N.B ${ }^{1}$ \\ Ngatek Global Services Limited,(NGSL),PMB 15, post code 543101,Ugep, Yakurr LGA, \\ Cross River State, Nigeria.. \\ ${ }^{1}$ Corresponding Author: Ngang Bassey Ngang, \\ nbngang@gmail.com, nbngan@yahoo.com Tel:+2348029662752,, +2348035102752
}

Abstract

The instability of power supply has arisen as a result of slow rotation of the turbine. This can be overcome by designing a membership function that will analyze the causes of slow turbine rotation, designing a membership function that will increase the rotation of a turbine, designing a fuzzy rule that will generate constant power supply when the turbine rotates fast and designing a model for Hydropower generator speed control using fuzzy software .tool,. The result obtained is stable power supply which has arisen because of increase in speed rotation of the turbine and increase in the water flow through the hydropower penstock when fuzzy is incorporated in the model. The speed rotation of the turbine result obtained when fuzzy controller is used is better than the proportional integral (PI).

Key words: turbine,slow rotation, hydropower

\subsection{INTRODUCTION.}

Hydropower plants are designed to generate electrical or mechanical power based on the demand for energy of the surrounding locality.

Due to variation of load the generated frequency of a generating plant fluctuates. Consumers demand for electricity makes the load of a hydropower generator to continuously change. With a change in generator load, the turbine load of hydropower station changes as well. Change in the load of hydro turbine causes a change in its rotation speed thereby resulting in a difference between its actual speed and rated speed. Thus, if a propeller turbine with full load suddenly becomes unloaded or with no load, its rotating speed increases to more two times the rated speed.

An increase in the load of a turbine makes its rotating speed less than the rated speed. It's always good to apply a load that will make the turbine and hence the generator, to operate within the range of their rated speeds so as not exceed their permissible strength. Making the rotation speed of a turbine or generator to change too much makes the frequency or electric current (Ac) at $50 \mathrm{~Hz}$ or $60 \mathrm{~Hz}$, accordingly, depending on the convention.

A hydropower automatic speed governor is used to control the turbine output when a sudden load change occurs. This is to avoid the rotation speed of the turbine and generator to charge sharply due to load reduction or increase. Adjusting the water flow into the mini hydro turbine makes the turbine output meet the change of external load. Due to the swiftness or fastness of the load changes in the generator, artificial control method does not meet this requirement. This is why most hydropower stations are equipped with an automatic mechanical "governor" to regulate water flow through the penstock to the turbine blades. However, the complex structure of this governor coupled with its expensive price, makes it unsuitable for mini hydroelectric power stations. In its place, mini hydro electric generator uses water flow control valves to control the rotation of the speed. Again, electronic load (ELC) and dump load are used to balance the excessive electricity from the generator, thus ensuring stability in current flow, with competitive price. 
In this research, the research, having studied the foregoing extensively, employed the use of an intelligent agent "Neuro-fuzzy" to

Provide adequate stability to the flow of water through the penstock to the turbine blades so that a steady speed is maintained by both the generator and the turbine. This takes care of sudden load changes which other methods so far used in this type of study have not taken care of.

Designing a membership function that will analyze the causes of slow turbine rotation, designing a membership function that will increase the rotation of a turbine, designing a fuzzy rule that will generate constant power supply when the turbine rotates fast and designing a model for Hydropower generator speed control using fuzzy software .tool.

\subsection{Methodology}

To design a membership function that will analyze the causes of slow turbine rotation.

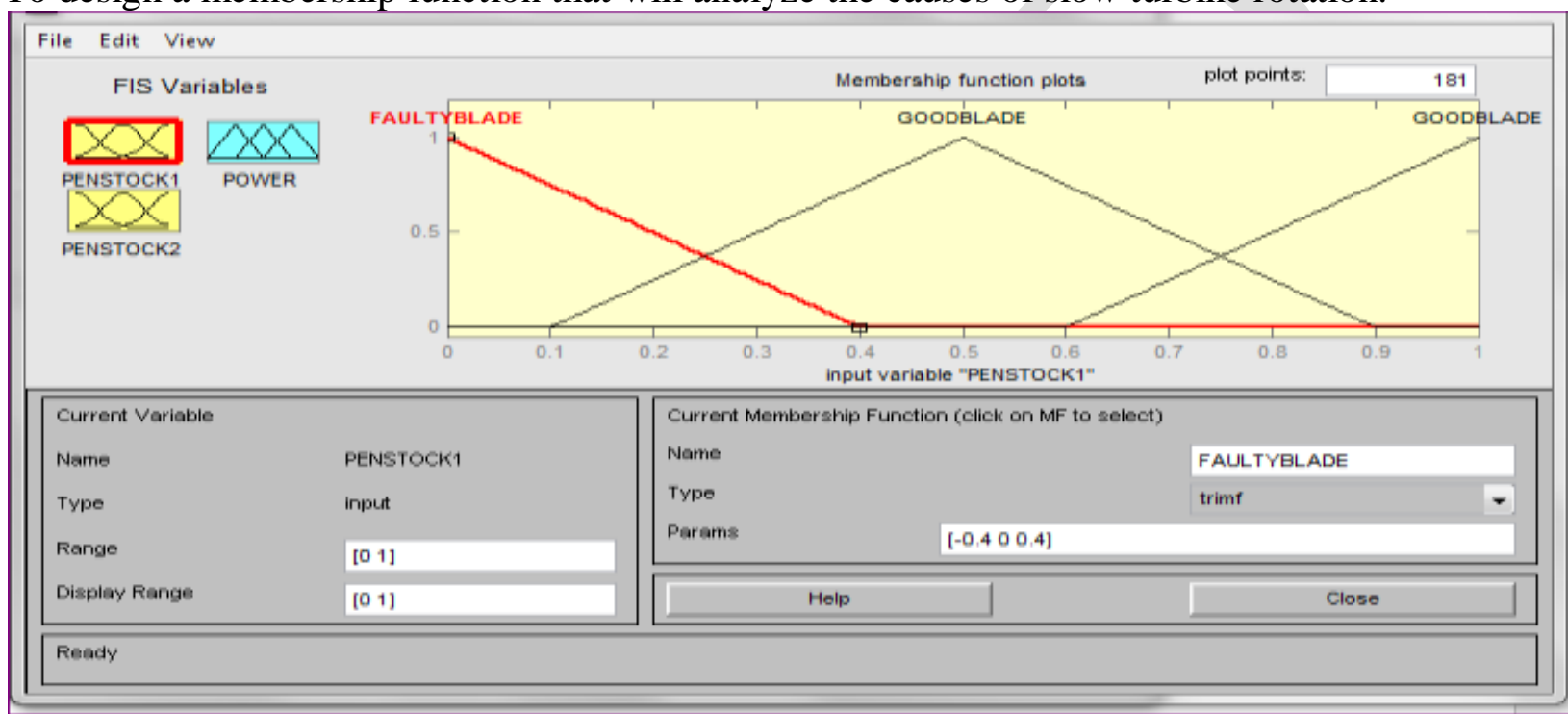

Fig 1 designed membership function that will analyze the causes of slow turbine rotation.

Fig 1 shows designed membership function that will analyze the causes of slow turbine rotation. Fig 1 analysis when the turbine blade is faulty and good.

To design a membership function that will increase the rotation of a turbine.

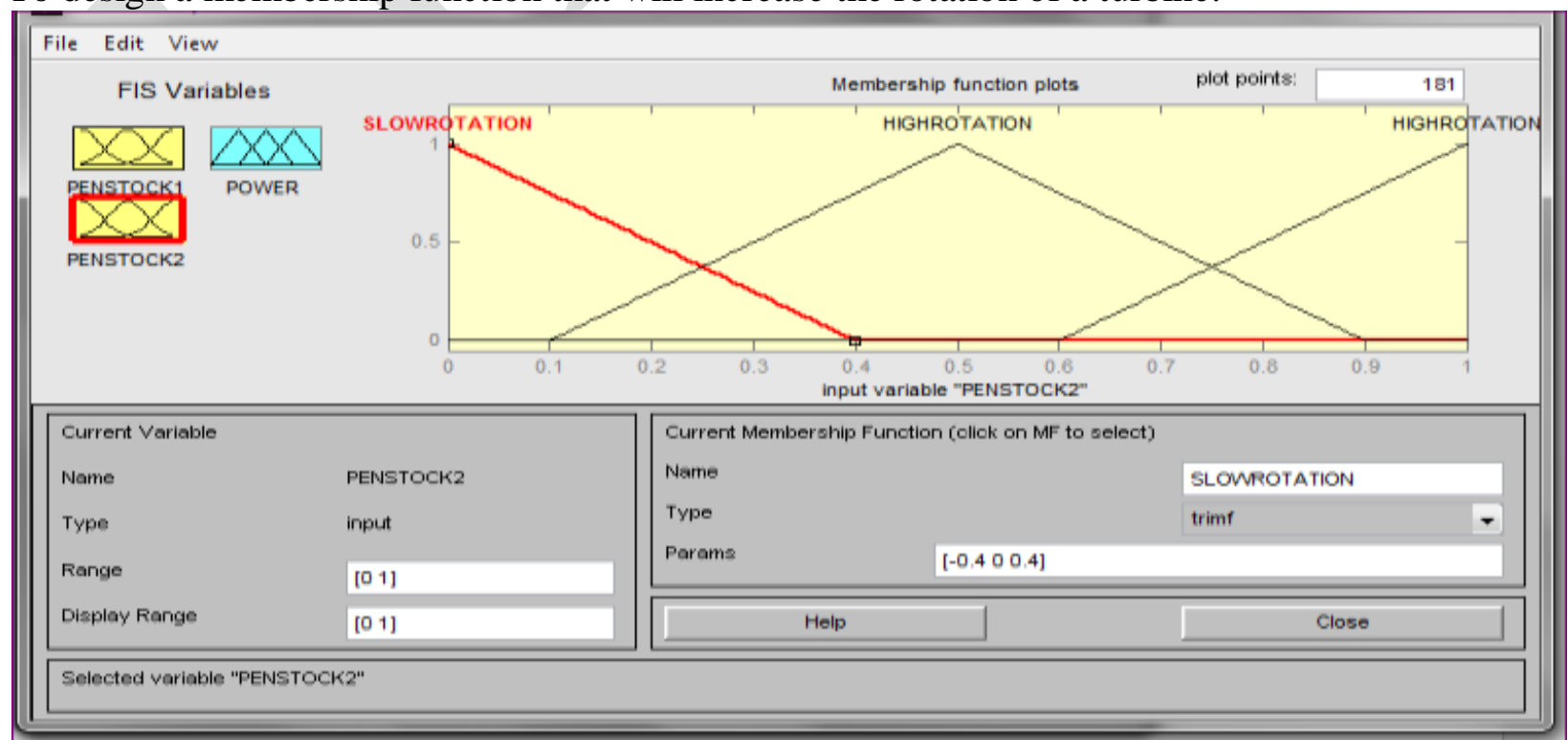

Fig 2 designed membership function that will increase the rotation of a turbine. 
Fig 2 shows designed membership function that will increase the rotation of a turbine. Fig 2 shows that the rotation of the turbine blade is high when it is not faulty. On the other hand, the rotation of the turbine is slow when it is faulty.

To design a fuzzy rule that will generate constant power supply when the turbine rotates fast.

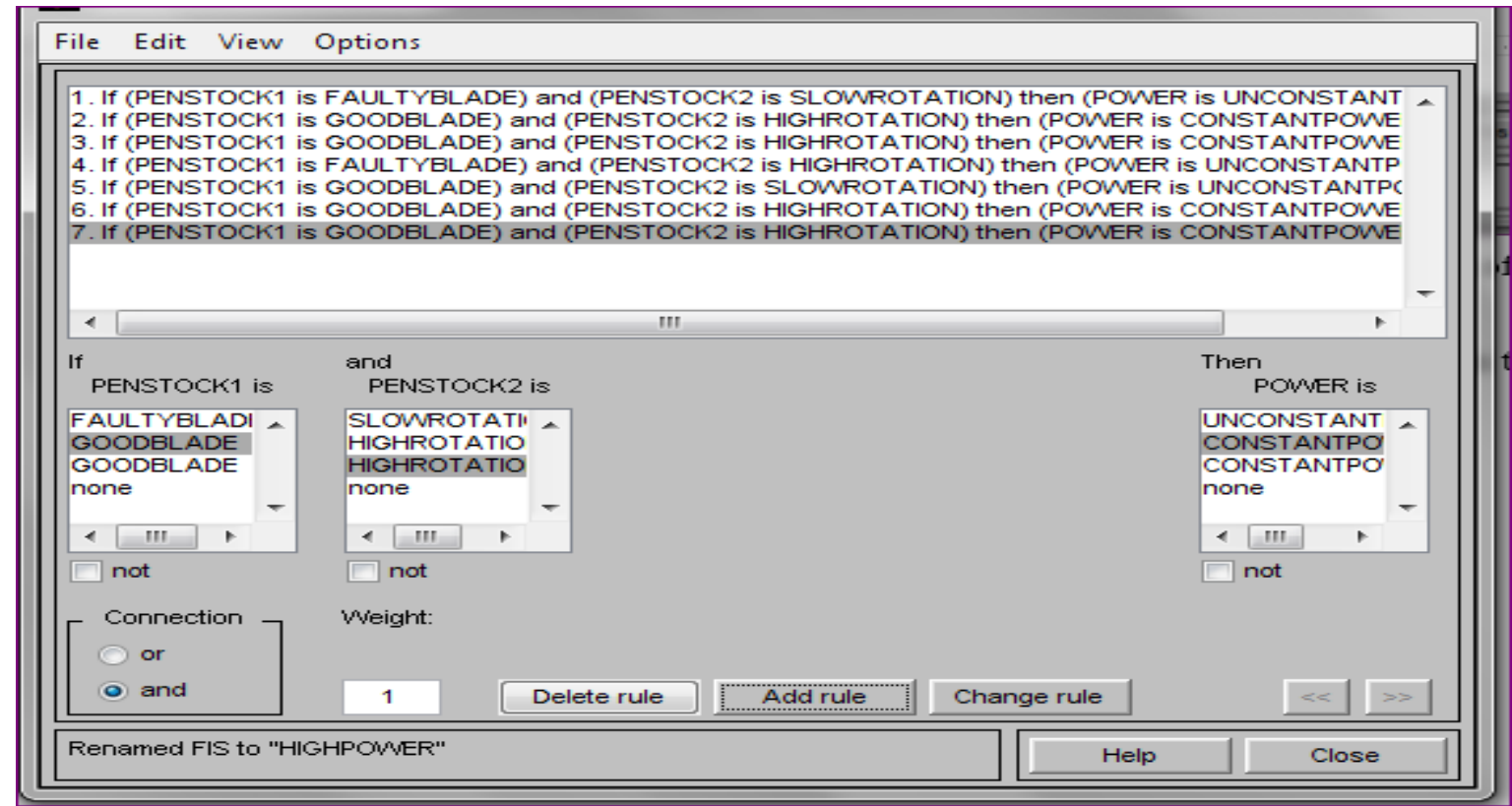

Fig 3 designed fuzzy rule that will generate constant power supply when the turbine rotates fast.

Fig 3 Shows designed fuzzy rule that will generate constant power supply when the turbine rotates fast. Fig 3 is a rule that sticks strictly to the fast rotation of the turbine thereby enhancing stable power supply.

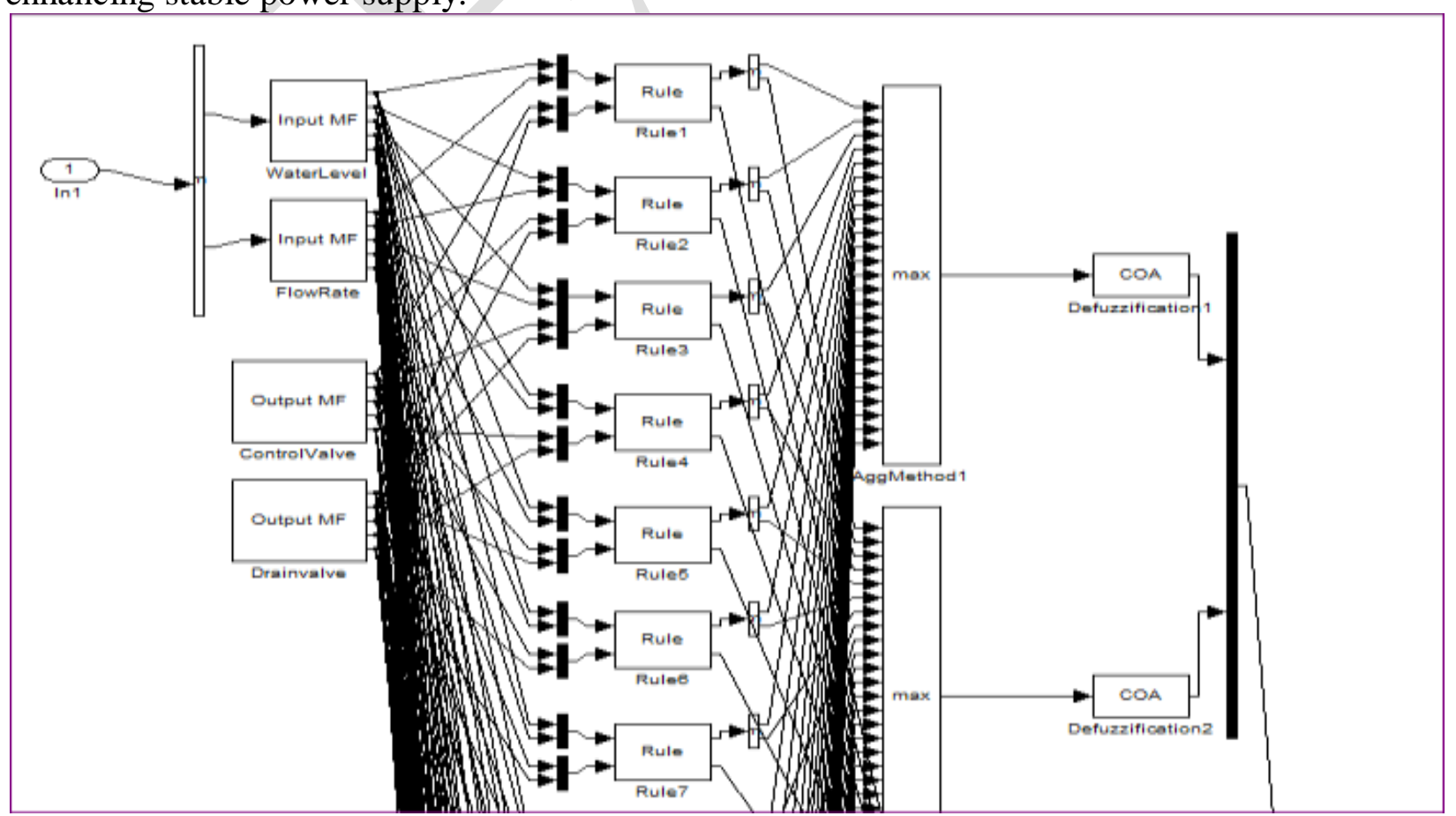

Fig 4 designed fuzzy rule that will generate constant power supply when the turbine rotates fast. 
Fig 4 shows designed fuzzy rule that will generate constant power supply when the turbine rotates fast. This occurs when the rule is imbibed in the fuzzy block for its effective increase of the turbine rotation and a stable power supply.

To design a model for Hydropower generator speed control without using fuzzy software .tool.

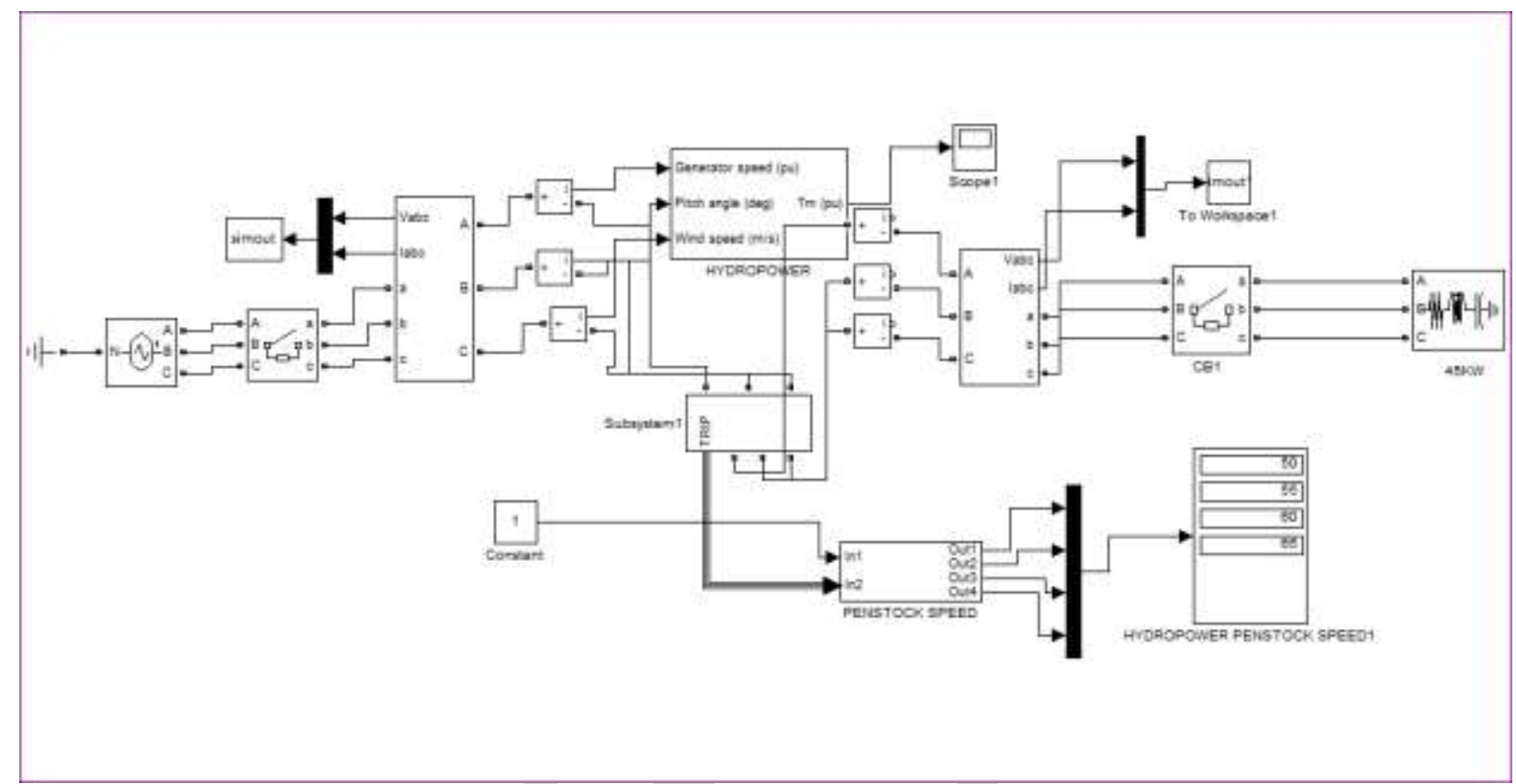

Fig 5 designed model for Hydropower generator speed control without using fuzzy software tool.

Fig 5 Shows designed model for hydropower generator speed control without using fuzzy software. The result

Obtained is a decrease speed of the penstock as shown in table 1.

To design a model for Hydropower generator speed control using fuzzy software tool.

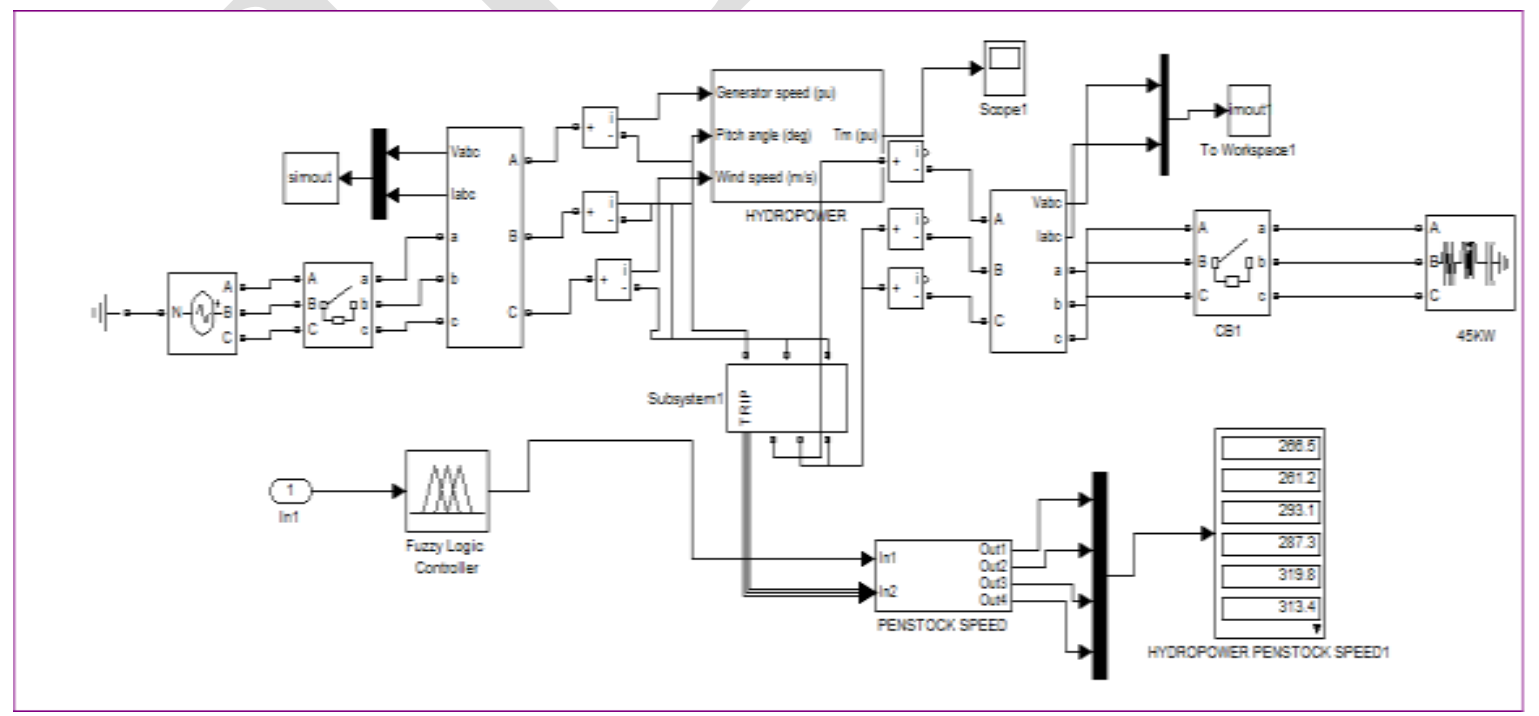

Fig 6 designed model for Hydropower generator speed control using fuzzy software tool.

Fig 6 Shows designed model for hydropower generator speed control using fuzzy software tool. The result obtained is an increased speed of the penstock rotation thereby enhancing stable power supply as shown in table 2 . 


\subsection{Result Analysis}

Table 1 HYDROPOWER TURBINE ROTATION SPEED WITHOUT FUZZY VS TIME

\begin{tabular}{|c|c|}
\hline $\begin{array}{c}\text { HYDROPOWER TURBINE ROTATION } \\
\text { SPEED WITHOUT FUZZY }\end{array}$ & TIME(S) \\
\hline 50 & 1 \\
\hline 55 & 2 \\
\hline 60 & 3 \\
\hline 65 & 4 \\
\hline
\end{tabular}

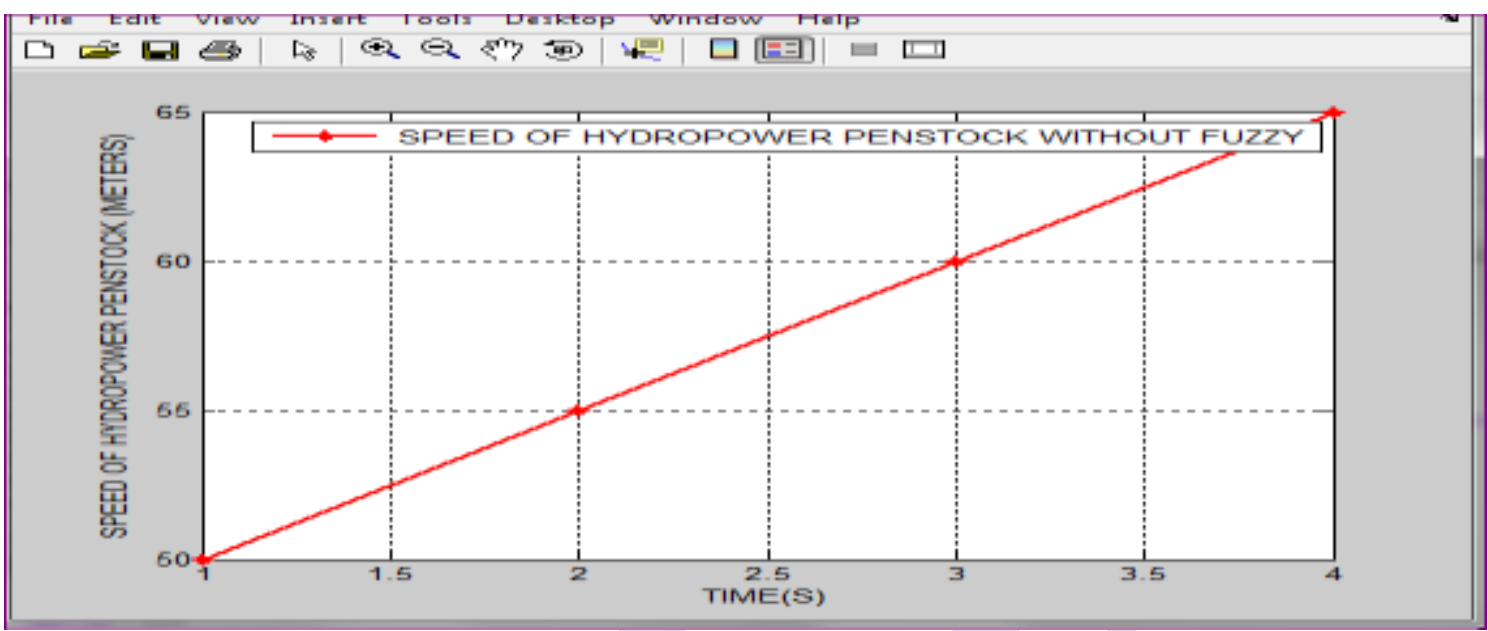

Fig 7 hydropower turbine rotation speed without fuzzy vs time

Fig 7 shows hydropower turbine rotation speed without fuzzy vs time. The highest speed of hydropower turbine rotation verse time coordinate occurred at $(65,4)$ while the least occurred at $(50,1)$ respectively.

Table 2 HYDROPOWER TURBINE ROTATION SPEED WITH FUZZY VS TIME

\begin{tabular}{|c|c|}
\hline $\begin{array}{c}\text { HYDROPOWER TURBINE ROTATION } \\
\text { SPEED WITH FUZZY }\end{array}$ & TIME(S) \\
\hline 266.5 & 1 \\
\hline 287.3 & 2 \\
\hline 313.4 & 3 \\
\hline 319.8 & 4 \\
\hline
\end{tabular}

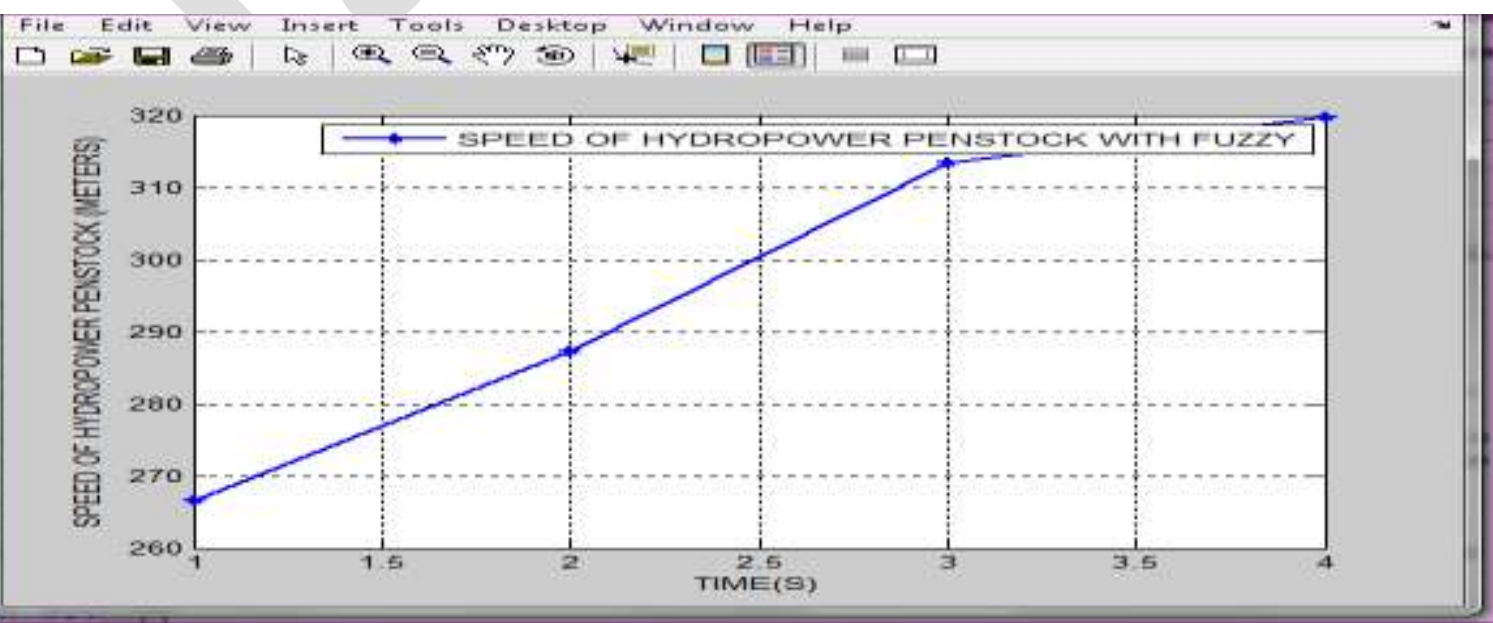

Fig 8 hydropower turbine rotation speed with fuzzy vs time 
Fig 8 Shows hydropower turbine rotation speed with fuzzy vs time. In fig 8 the highest speed of hydropower turbine with fuzzy verse time occurred at $(319.8,4)$ while the least occurred at $(266.5,1)$.

Table 3 COMPARING HYDROPOWER TURBINE ROTATION SPEED WITHOUT AND WITH FUZZY VS TIME

\begin{tabular}{|c|c|c|}
\hline $\begin{array}{c}\text { HYDROPOWER TURBINE } \\
\text { ROTATION SPEED } \\
\text { WITHOUT FUZZY }\end{array}$ & $\begin{array}{c}\text { HYDROPOWER TURBINE } \\
\text { ROTATION SPEED WITH } \\
\text { FUZZY }\end{array}$ & TIME(S) \\
\hline 50 & 266.5 & 1 \\
\hline 55 & 287.3 & 2 \\
\hline 60 & 313.4 & 3 \\
\hline 65 & 319.8 & 4 \\
\hline
\end{tabular}

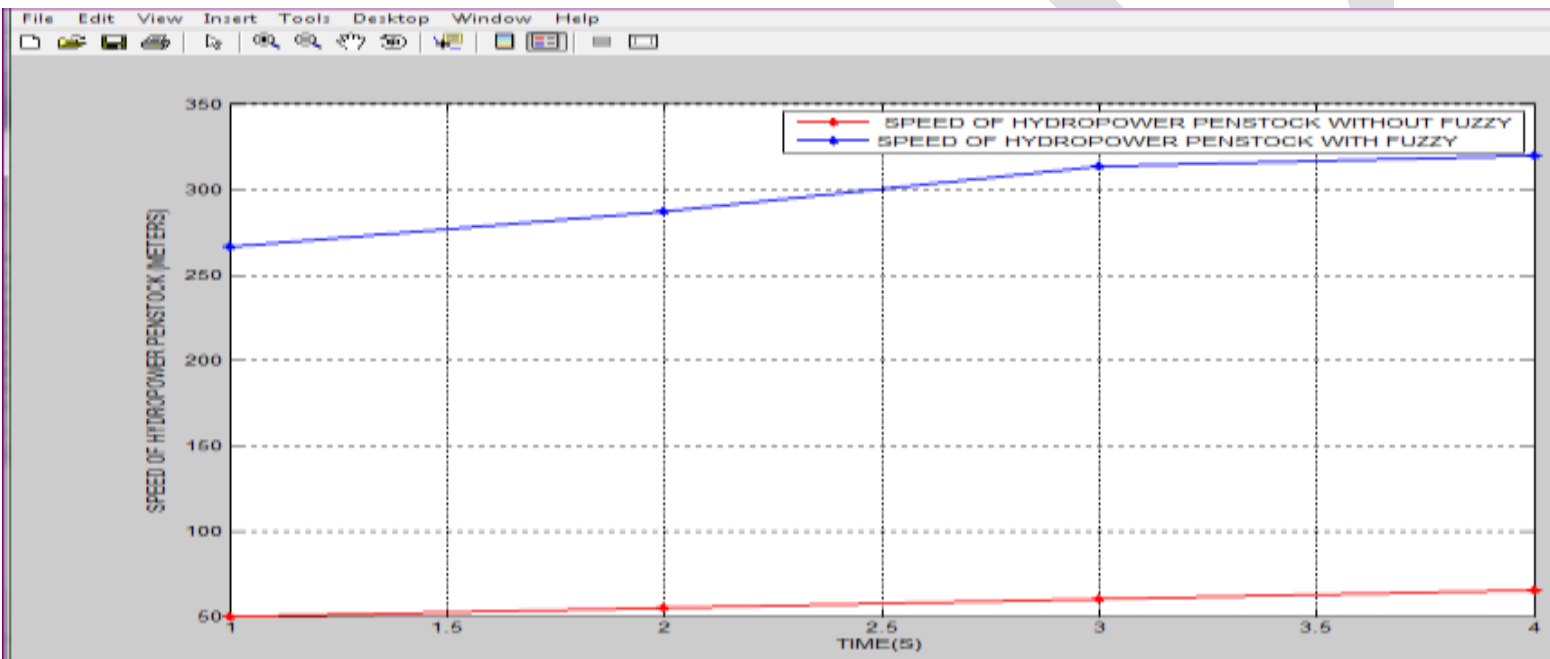

Fig 9 comparing result of hydropower turbine rotation speed without and with fuzzy vs time

Fig 9 shows comparing result of hydropower turbine rotation speed without and with fuzzy verse time. The result obtained shows that fuzzy gives higher speed rotation of the turbine than without fuzzy. The result also shows that fuzzy enhances stable power supply while without fuzzy causes intermittent power supply.

\subsection{Conclusion}

Power instability which has arisen as a result of low speed rotation of hydropower turbine; can be overcome by designing a membership function that will analyze the causes of slow turbine rotation, design a membership function that will increase the rotation of a turbine, designing a fuzzy rule that will generate constant power supply when the turbine rotates fast and designing a model for Hydropower generator speed control using fuzzy software .tool.

\section{References}

[1]Woodward J. L., "Hydraulic-Turbine Transfer Function for use in Governing Studies", Proceedings of the IEE, Vol. 115, pp. 424-426, March 1968.

[2] R. Oldenburger and J. Donelson, "Dynamic Response of a Hydroelectric Plant", Transactions of AIEE, Vol. 81, pp. 403-418, October 1962. 
[3] J. M. Undrill and J. L. Woodward, "Non-Linear Hydro Governing Model and Improved Calculation for

Determining Temporary Droop", IEEE Transactions on Power Apparatus and Systems, Vol. PAS-86, PP.443- 453 April 1967.

[4] IEEE Committee Report, "Hydraulic Turbine and Turbine Control Models For System Dynamic Studies", IEEE Transactions on Power Systems, Vol. 7, No. 1, pp. 167-179, February 1992.

[5] IEEE Committee Report, "Dynamic Models for Steam and Hydro Turbines in Power System Studies", IEEE, Transactions on Power Apparatus and Systems, Vol. PAS-92, No. 6, PP. 1904-1915, Nov./Dec. 1973.

[6] C. C. Young, "Equipment and System Modeling for Large Scale Stability Studies", IEEE Transactions on Power Apparatus and Systems, Vol. 91, pp.99-109, January 1972.

[7] D. G. Ramey and J. W. Skooglund, "Detailed Hydro governor Representation for System Stability Studies", IEEE Transactions on Power Apparatus and Systems, Vol PAS-89, No. 1, pp.106-112, January 1970.

[8] Working Group on Prime Mover and Energy Supply, "Hydraulic Turbine and Turbine Control Models for System Dynamic Studies", Models for System, Dynamic Performance Studies. IEEE Transaction on Power System, Vol. 7. No.1 pp. 167-179,February 1992. 